\title{
ASSESSING PORTFOLIO AND ASSET RETURNS OF SOME FINANCIAL AND NON- FINANCIAL COMPANIES ON THE GHANA STOCK EXCHANGE USING A 3-FACTOR MODEL
}

\author{
C. P. OGBOGBO AND N. ANOKYE-TURKSON
}

(Received 28 February 2021; Revision Accepted 24 May 2021)

\begin{abstract}
This study on the Ghana Stock Exchange (GSE), investigated, if the overall size of the market, affects the fundamentals of the Fama French 3-Factor model, and to ascertain if the Fama French model can be used effectively to assess portfolio and assets return for companies listed on the Ghana Stock Exchange. In this paper, portfolios of assets of companies on the Ghana Stock Exchange are constructed and analyzed using the Fama-French 3-factor model. The empirical data which consists of assets of 15 companies listed on the GSE, including assets of both financial and non-financial companies for good representation of the Ghana Stock Exchange. We found that the basic principle of the model is not satisfied. This is attributed to a number of factors which include overall size of the market, volume of trade, and high leverage (more debt than equity) associated with financial firms. High debt/equity ratio is linked to high risk.
\end{abstract}

KEYWORDS: Market Capitalization, Book-to-market ratio, Portfolio, Small minus big, High minus low

\section{$1.0 \quad$.INTRODUCTION}

An investor would like to make decisions that guarantee maximum returns and downsized risk. Modern day investors are interested in high returns for their investments. They constantly calculate the risk inherent in their investments. Risk factors that can affect return on investment include systematic or market risk, size risk and value risk.

In this work the Fama-French 3-factor model is used in the analysis of portfolios of assets of some companies, on the Ghana stock exchange. The 3- factor model developed by Fama et al,1992 is an asset pricing model. It extends the capital asset pricing model, (CAPM) by adding size risk and value risk factors, to the market risk factor. By incorporating other sources of risk, the model gives the portfolio manager direction on the source of risk. This is because Portfolio managers would be able to manage their risk exposures better, by identifying the true sources of risk. If stocks are priced rationally, differences in average returns are as a result of differences in risks. Fama et al., 1992 found that market equity and the ratio of book equity to market equity (BE/ME) are two variables that affect average stock returns. This work investigates how this model performs with respect to returns of stocks on the GSE. Thus, in this paper portfolios of assets of companies on the GSE are constructed and analyzed using the model. Various criteria are used in constructing the portfolios, taking into consideration, the strength and performance of the various companies.

The aim of this paper is to analyze some portfolio generated from assets of some companies on the GSE, and determine if the portfolios' rates of return can be predicted using the Fama French 3-Factor model. The size of company is a factor in the Fama- French model, and the size of company is relative to the overall market size. The Ghanaian economy is a growing economy, and the GSE is not very big. Whereas the American stock exchange in 2017, traded 39.8 trillion dollars, Ghana stock exchange traded 117.28 million dollars in the same year. Considering the size of GSE and Ghana Economy, we test the model on empirical data from the GSE, to ascertain its performance for a small market and Economy. The question is; will the fundamentals of the Fama- French model be satisfied in this case. Will good results be obtained in terms of assessing returns and risk. The study investigates, if the overall size of the market, affects the fundamentals of the Fama French 3Factor model. Since the assets of companies on the

C. P. OGBOGBO, Department of Mathematics, University of Ghana. Legon.

N. ANOKYE-TURKSON, Department of Mathematics, University of Ghana. Legon. 
GSE are being considered, source of data used is the Ghana stock exchange. A five year period of study is considered (2015-2019). Some works have been done on some exchanges using the Fama- French 3-factor model. Sreenu, N.,2018 conducted a study with the purpose of examining the applicability of the Fama French 3- Factor model, alongside the CAPM, with an emphasis on its main components, namely the investment analysis, risk-free rate, beta and other related components. He found that, the Fama French 3factor model has the ability to provide better explanation to the variation in the expected rate of return and was able to predict the portfolios' rates of return more accurately than the other pricing model such as the CAPM. For the work by Griffin, J. M., 2002, the aim of the study was to modify the original Fama-French 3Factor and determine that the modified version works better than the original model. He found that FamaFrench factors are country-specific; domestic economic factors have higher influence than global ones. Rehnby, N.,2016 in his work, used the risk-free interest rate as the one-month Treasury bill issued by the Swedish National Debt Office. His results show that value stocks and small market capitalization stocks outperform growth stocks and big market capitalization stocks, this is in line with the main findings of Fama et al.,2004. Robert Faff, 2004, tested the Fama French 3 -factor model using empirical daily Australian data and obtained evidence favorable to the model, i.e. small companies outperform big companies and that value stocks outperform growth stocks. However he discussed the size effect of the model from a different perspective. Instead of 'outperformance', they viewed small cap companies as 'performing differently' from large cap companies. Based on monthly data of Pakistan financial and non-financial firms, from 2002 to 2016. Ali, et al., 2018 showed that the Pakistani stock market is satisfactorily explained by the Three-Factor Model, especially with the addition of SMB and HML. They also found that that value stocks outperform growth stocks.

Not much work has been done on the GSE using the Fama-French model. However, Acheampong et al., 2015, did some work on the GSE using the model, but only for non- financial firms. In their work, which concluded that the Fama-French Model explains excess portfolio returns better, they used assets of non-financial assets, listed and delisted on GSE for the period 20022011. They formed a six-stock portfolio for the work, and found SMB, (small minus big), to be negative. This implies the size effect is weak considering the Ghana Stock market. BTM (book-to-market) factor and HML (high minus low) were positive in their work, implying that there is a strong BTM effect on the returns on the Ghana Stock Exchange. The result obtained in this paper differs slightly from Acheampong's result for the following reasons. The time period of his work was from 2002 to 2011 while this work focuses on a recent time, 2014 to 2019. The study period of his work was chosen because of the improvement of the workings of the exchange, as well as increased number of companies listed on the exchange during that period. It reflected a period of growth in the market and boost for the Ghanaian capital market, hence a rise in the market capitalization of the GSE. The period under study in this paper includes a period when the Bank of Ghana experienced a banking sector reform. In this work financial and non-financial companies are considered to give a true reflection of the activities of the GSE. During the period of our study, the financial companies were found to be more volatile than the non-financial companies. Acheampong in his work considered only non-financial assets because financial firms normally have high leverage (i.e. more debt than equity). A high debt/equity ratio is often associated with high risk. Moreover the implication of high leverage to financial firms is different from the non-financial firms. The rest of the paper is presented as follows: In section 2, the model and its application on the assets and portfolios on the GSE are presented. In the third section, results are displayed and analysis is done. Conclusion is drawn in section 4.

\subsection{THE MODEL AND ITS APPLICATION ON ASSETS AND PORTFOLIOS OF COMPANIES ON THE GSE 2.1THEORETICAL FRAMEWORK}

Market capitalization is crucial in the model, it is obtained as the product of Share price and number of outstanding shares, it depicts volume of trade for each company. Fama and French found that the systematic risk $\beta_{t}$, is not the only risk to worry about. They suggested that there are two other risk values $\beta_{v}$ (from average valuation of companies) and $\beta_{\text {size }}$ (from their average size), with respect to size of firms, book-tomarket values and excess return on the market. The three factors used are SMB (small minus big), HML (high minus low) and the portfolio's return less the risk free rate of return. SMB accounts for publicly traded companies, with small market capitalization that generate higher returns. HML on the other hand, accounts for value stocks with high book-to-market ratios that generate higher returns in comparison to the market.

The model considers small companies to be riskier than large companies, they are compensated with higher returns, from the finding of Fama et al. 2020. The model also incorporates company valuations, and it is assumed that Value Companies will yield higher returns. Thus, low stock prices may attract investors and increase in returns. It is noteworthy that, in the USA, market capitalization greater than one trillion dollars is for big companies. For the Ghanaian market, we considered market capitalization of $0-500$ million Cedis as small, while 500 million Cedis and above, is considered big. The model equation is given below in equation (1) $R_{i}-R_{f}=\alpha+\beta_{t}\left(R_{m}-R_{f}\right)+\beta_{\text {size }} S M B+\beta_{v} H M L+\epsilon_{i}$

where $R_{i}$ is expected total return of a stock, or portfolio, $R_{f}$ is risk-free interest rate, $\alpha$ is the abnormal rate of return on security in excess of that predicted by CAPM, $R_{m}$ is the market return, $R_{i}-R_{f}$ is expected excess return, $R_{m}-R_{f}$ is excess return on the market portfolio (index), SMB, the size premium (Small minus Big), is the historic excess returns of the Small Cap companies over large Cap companies, HML, the value premium, (High minus Low) is the historic excess returns of value stocks, (high book-to-market ratio) over growth stocks (low book-to-market ratio), the betas are the factor's coefficient (sensitivity) i.e. $\beta_{t}$ is sensitivity with respect to excess return on the market, $\beta_{\text {size }}$ is sensitivity with respect to size premium, $\beta_{v}$ is sensitivity with respect to 
value premium, and $\epsilon$ is residual of the regression model. $\boldsymbol{\beta}_{\text {size }}$ and, $\boldsymbol{\beta}_{v}$ are determined by linear regressions and can take negative values as well as positive values.

\subsubsection{SIZE AND BOOK TO MARKET RATIO: STOCK RETURN AND PROFITABILITY}

Let $E I(t)$ be equity income for the year ending in calendar year $t$. Let $B E(t-1)$ be the book value for common equity for year $t$.

Then the measure of profitability is $E I(t) / B E(t-1)$. $E I(t) / B E(t-1)$ is the sum of $E I_{i}(t)$ for all firms $i$ in a portfolio, divided by the sum $B E_{i}(t-1)$

(Return on book equity of a firm resulting from merging all firms in the portfolio).

We consider relationship between $B E / M E$ and the expected stock returns and proceed as follows:

Let $\mathrm{D}(\mathrm{t})$ be dividend paid by the firm in any year,

$$
D(t)=E I(t)-D P(t)-I(t)
$$

Where, $D P(t)$ is depreciation and $I(t)$ is investment outlays.

Supposed at time $t$, expected depreciation and investment for any year $t+i$ are proportional to expected future equity income i.e.

$$
\begin{aligned}
\mathbb{E}[D(t+i)] & =\mathbb{E}[E I(t+i)+D P(t+i)-I(t+i)] \\
& =\mathbb{E}\left[E I(t+1)\left(1+K_{1}-K_{2}\right)\right]
\end{aligned}
$$

$K_{1}$ and $K_{2}$ are proportionality factors. If the discount rate $r$, for expected dividends is constant, then value of market equity at $t$, is given as

$$
M E(t)=\left(1+K_{1}-K_{2}\right) \sum_{i=1}^{\infty} \frac{\mathbb{E}[E I(t+i)]}{(1+r)^{i}}
$$

Then we obtain the market-to-book-ratio

$$
\frac{M E(t)}{B E(t)}=\left(1+K_{1}-K_{2}\right)\left(\sum_{i=1}^{\infty} \frac{E_{t} \mathbb{E} E I(t+1) / B E(t)}{(1+r)^{i}}\right.
$$

From the foregoing, it is predicted that firms with higher required equity returns, $r$, will have higher book to market ratios. Equations (2) and (3) state that brief periods when equity income is expected to be high or low relative to book equity, do not have much effect on market equity and the book -to-market-ratio. Thus, the prediction is that high $\mathrm{BE} / \mathrm{ME}$ (low stock price relative to book value), should be associated to low earnings on book equity; while low $\mathrm{BE} / \mathrm{ME}$ (high stock price relative to book value), should be associated with persistently strong $E I / \mathrm{BE}$, i.e., firms with high average returns growth stocks.

\section{ASSESSING PORTFOLIOS AND ASSETS OF COMPANIES ON THE GHANA STOCK EXCHANGE USING THE MODEL: MATERIALS AND METHODS Data for the model.}

A basic material for this empirical work is the data used in the model. The parameters of the model are obtained for the Ghanaian Stock Market. Five-year data are used (2015 - 2020). This choice is also informed by a study performed by Bartholdy, et al., 2005. The Bank of Ghana, BOG, and Ghana Stock Exchange maintain an extensive, regularly updated, and publicly available data library; therefore, data for individual stocks, Market trend data, including the Risk-free rate of return $\left(R_{f}\right)$ and Market return $\left(R_{m}\right)$, were obtained from their websites. Stock price data from December, 2015 through February, 2020 were collected for fifteen (15) companies namely; CAL Bank Ghana, Ghana Commercial Bank, Fan Milk Limited, Ghana Oil, MTN Ghana, Aluworks Limited, SIC Insurance Company, Societe Generale Bank, Unilever Ghana, PZ Cussons, Total Petroleum Ghana Limited, Clydestone Ghana limited, Mechanical Lloyd Company Limited and Guinness Ghana Breweries. Monthly stock Prices (in cedis) of the selected 15 companies (2015 - 2020) are shown in Figs 1-15 below. 
CAL

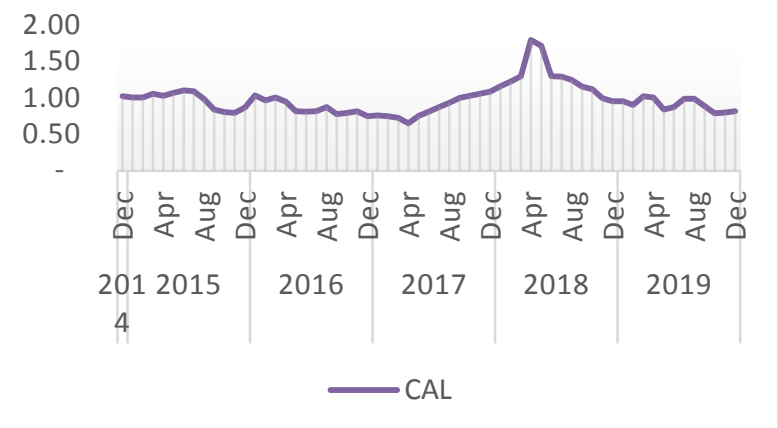

Fig 1: Monthly Average Stock Prices for CAL Bank Bank

\section{SCB}

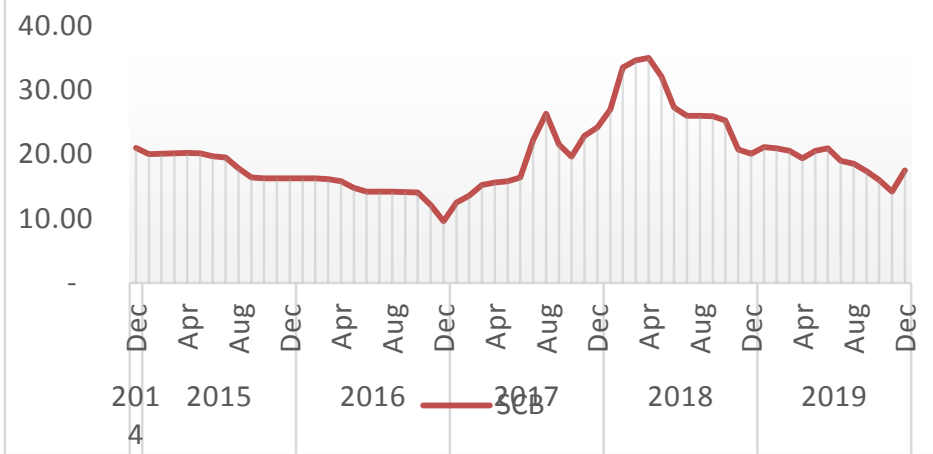

Fig 2: Monthly Average Stock Prices for Standard Chartered

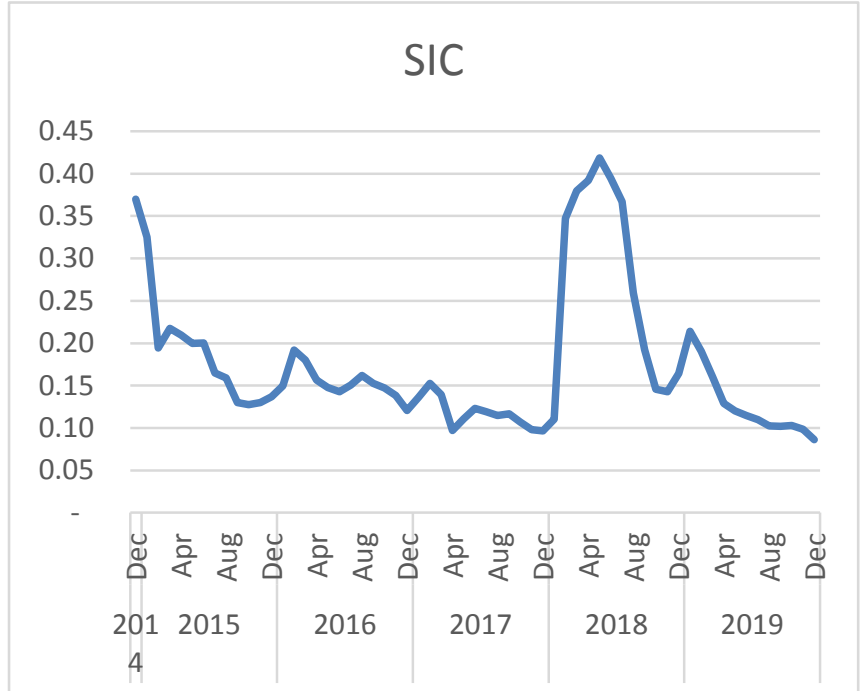

\section{PZC}

0.60

0.50

0.40

0.30

0.20

0.10

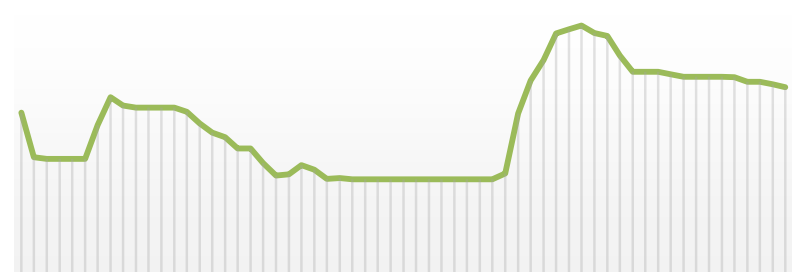

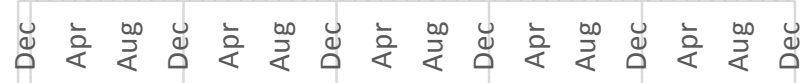
\begin{tabular}{cc|c|c|c|c}
201 & 2015 & 2016 & 2017 & 2018 & 2019 \\
4 & & & & &
\end{tabular} $\longrightarrow$ PZC

Fig 3: Monthly Average Stock Prices for SIC Insurance Limited

Fig 4: Monthly Average Stock Prices for PZ Cussons

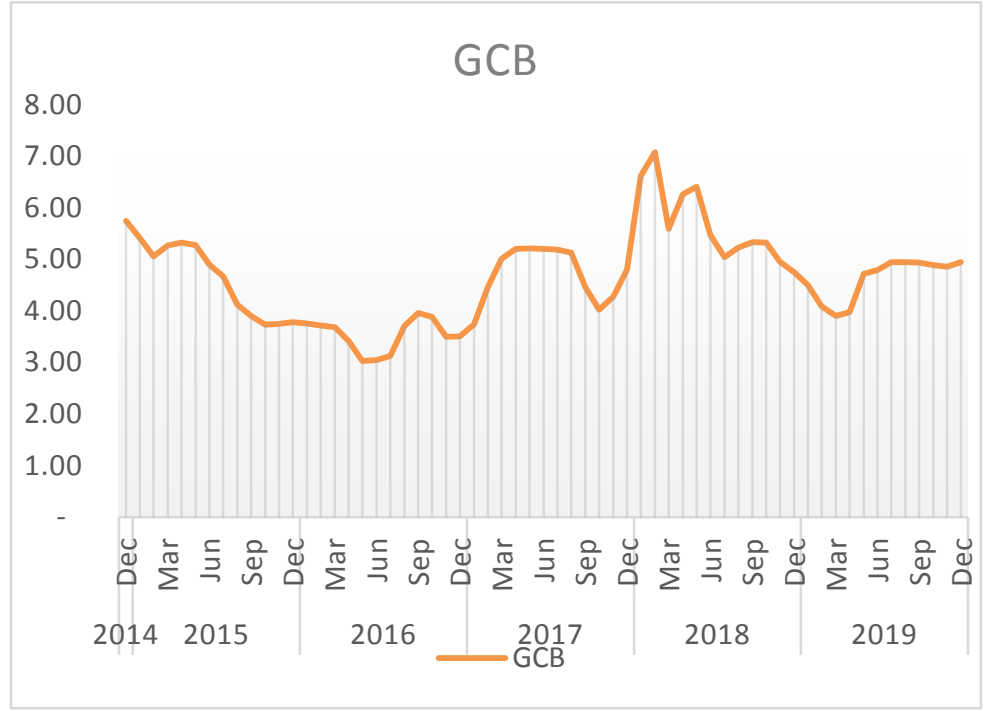

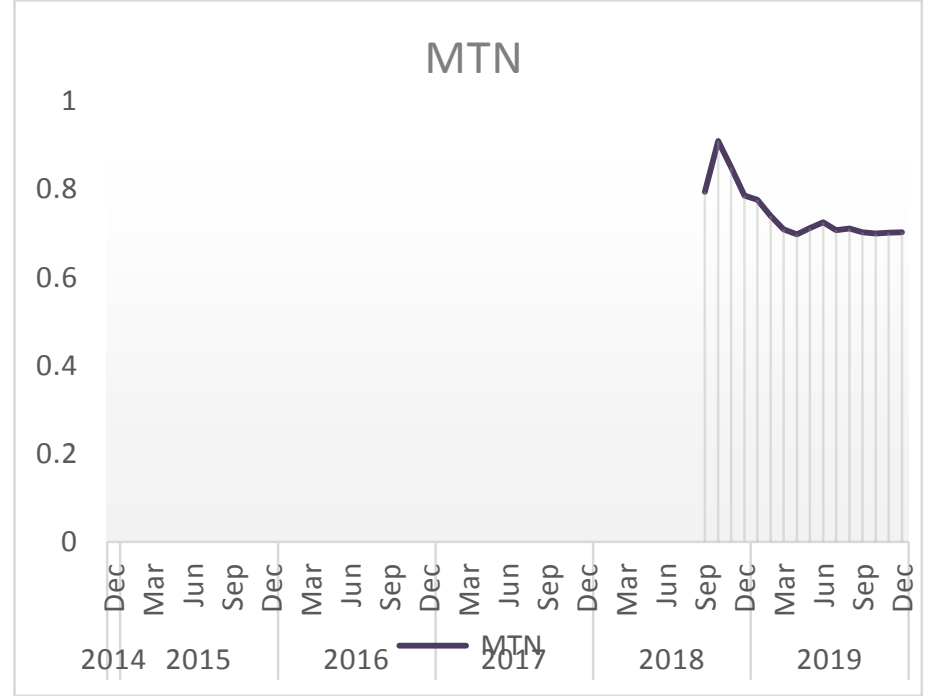

Fig 5: Monthly Average Stock Prices for Ghana Commercial Bank Fig 6: Monthly Average Stock Prices for MTN Ghana 


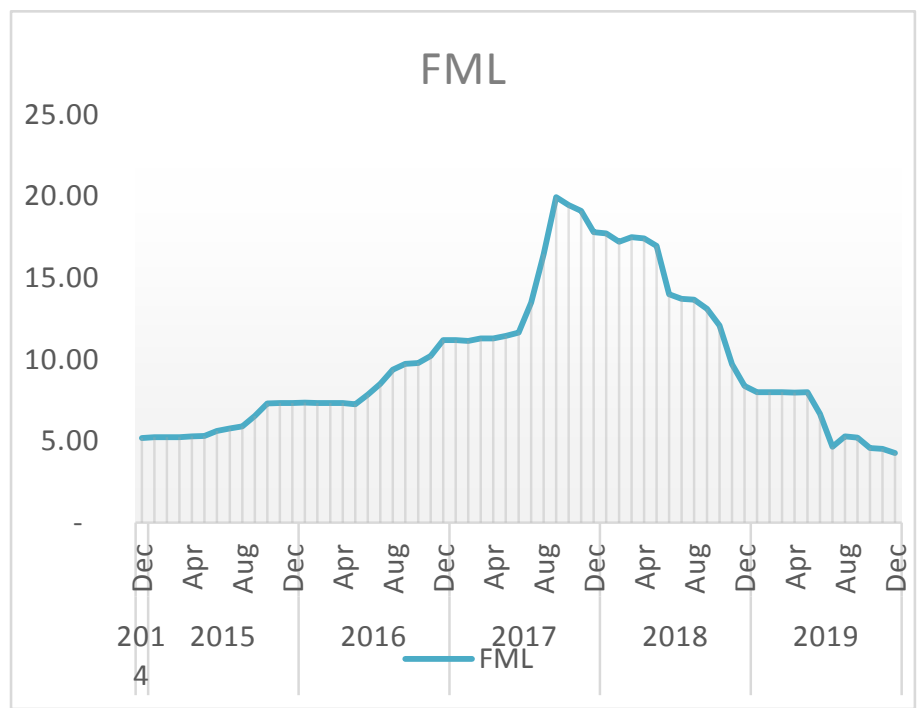

Fig 7: Monthly Average Stock Prices for FanMilk Ghana

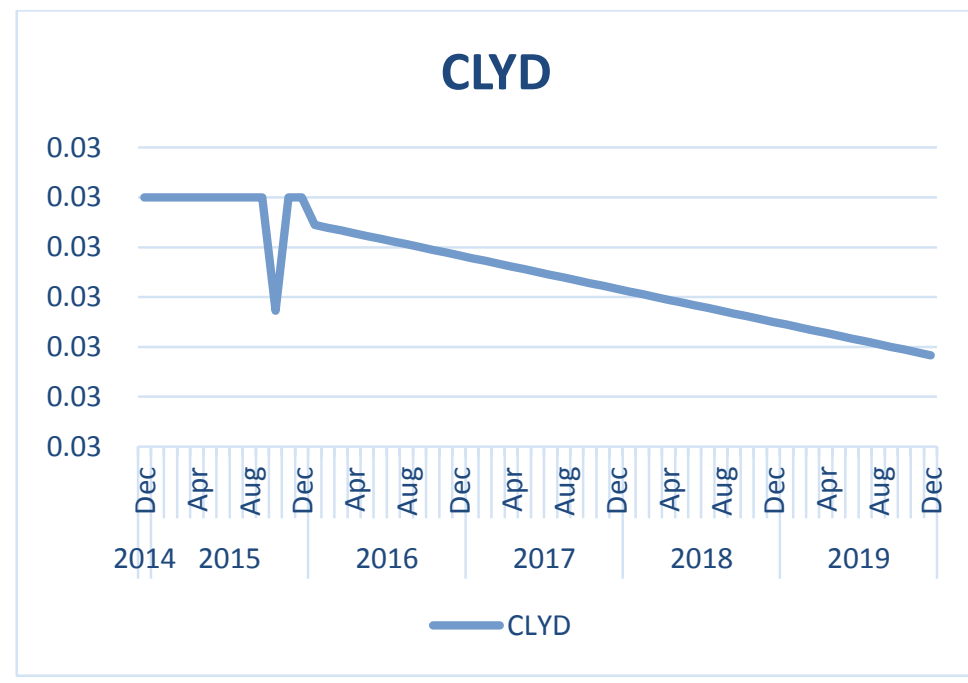

Fig 8: Monthly Average Stock Price for Clydestone Ghana limited

20.00

Fig 9: Monthly Average Stock Prices for Ghana Oil Company Fig 10: Monthly Average Stock Prices for Uniliver Ghana

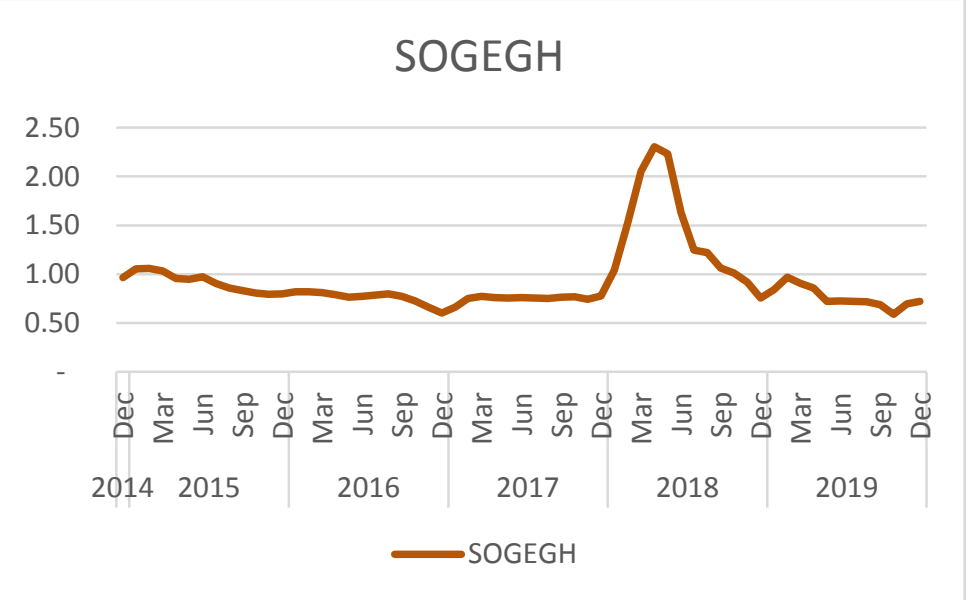

\section{ALW}

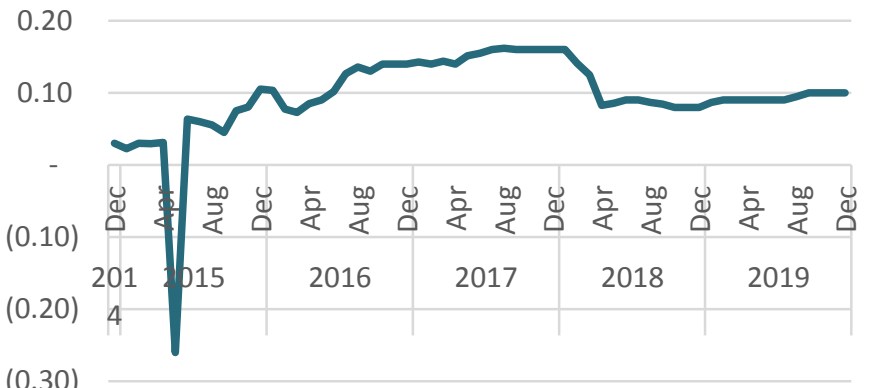

(0.30)

Fig 11: Monthly Average Stock Prices for Société Générale Ghana Fig 12: Monthly Average Stock Prices for Aluworks Ghana 


\section{GGBL}

3.50

3.00

2.50

2.00

1.50

1.00

0.50

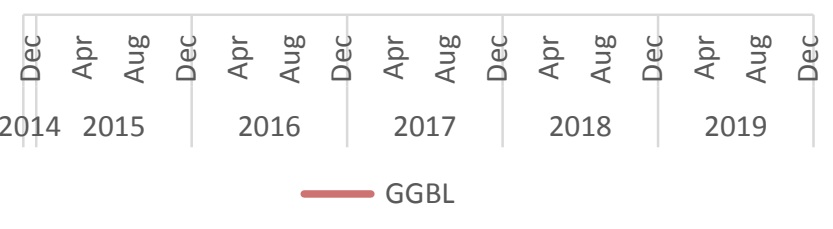

Fig 13: Monthly Average Stock Prices for Guinness Ghana Breweries Company

TOTAL

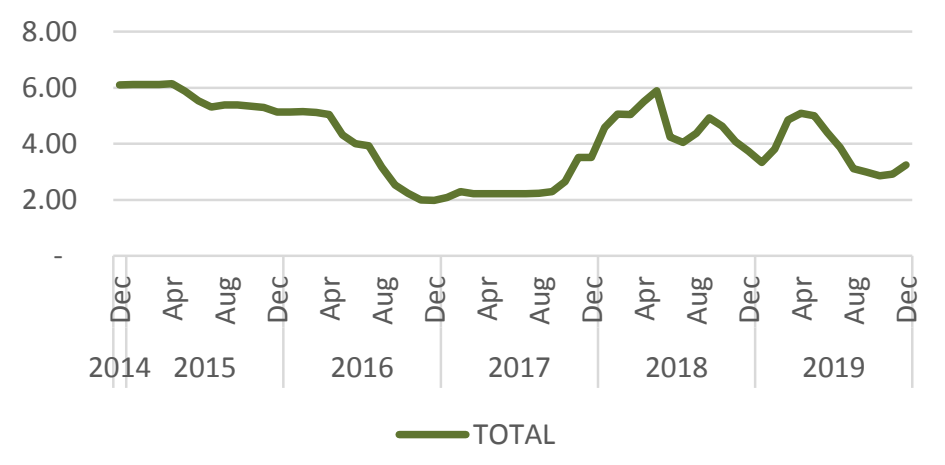

\section{MLC}

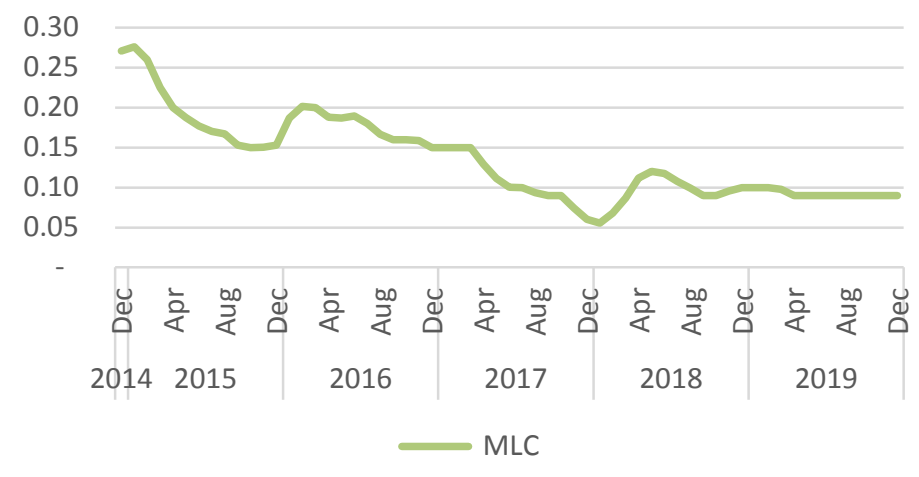

Fig 14: Monthly Average Stock Prices for Mechanical Lloyd Company

Fig 15: Monthly Average Stock Prices for Total Petroleum Ghana Limited 


\subsubsection{COMPUTATION OF FACTORS USED IN THE MODEL}

\section{Small Minus Big (SMB)}

The Fama and French Three Factor model's size factor is constructed by dividing the dataset into two groups, the limit is the 50th percentile. The companies are then either in a small group (0-50\%) or a large group (50-100\%). The six portfolios used in calculating SMB are constructed by sorting the companies into a Small/Low, Small/Medium, Small/High, Big/Low, Big/Medium and Big/High portfolios. SMB factor is obtained as follows:

Where

$$
\boldsymbol{S M B}=\frac{\left(R_{S \backslash L}\right)+\left(R_{S \backslash M}\right)+\left(R_{S \backslash H}\right)}{3}-\frac{\left(R_{B \backslash L}\right)+\left(R_{B \backslash M}\right)+\left(R_{B \backslash H}\right)}{3}
$$

$\boldsymbol{R}_{\boldsymbol{S} \backslash L}=$ Return of Small companies with low book- to- market ratio

$\boldsymbol{R}_{S \backslash M}=$ Return of Small companies with medium book -to- market ratio

$\boldsymbol{R}_{\boldsymbol{S} \backslash \boldsymbol{H}}=$ Return of Small companies with High book- to- market ratio

$\boldsymbol{R}_{\boldsymbol{B} \backslash \boldsymbol{L}}=$ Return of Big companies with low book - to- market ratio

$\boldsymbol{R}_{\boldsymbol{B} \backslash M}=$ Return of Big companies with medium book- to- market ratio

$\boldsymbol{R}_{\boldsymbol{B} \backslash \boldsymbol{H}}=$ Return of Big companies with High book- to- market ratio

\section{High Minus Low (HML)}

The companies are ranked by their BE/ME ratio, the companies are divided into three groups, low $0 \%-30 \%$, medium 40\%-70\% and high 70\%-100. As stated above, six portfolios are created Small/Low, Small/Medium, Small/High, $\mathrm{Big} / \mathrm{Low}$, Big/Medium and Big/High. Average return is calculated for every portfolio and the returns are taken from January to December each year. HML factor is given as:

Where,

$$
\boldsymbol{H} \boldsymbol{M L}=\frac{\left(R_{S \backslash H}\right)+\left(R_{B \backslash H}\right)}{\mathbf{2}}-\frac{\left(R_{S \backslash L}\right)+\left(R_{B \backslash L}\right)}{\mathbf{2}}
$$

$\boldsymbol{R}_{\boldsymbol{S} \backslash \boldsymbol{H}}=$ Return of Small companies with High book- to- market ratio

$\boldsymbol{R}_{\boldsymbol{B} \backslash \boldsymbol{H}}=$ Return of Big companies with High book- to- market ratio

$\boldsymbol{R}_{S \backslash L}=$ Return of Small companies with low book- to- market ratio

$\boldsymbol{R}_{\boldsymbol{B} \backslash L}=$ Return of Big companies with low book- to- market ratio

\subsubsection{METHODS}

From the obtained daily historical prices, monthly average stock prices and monthly average returns on stocks for the period under study (January, 2015 to February, 2020), were calculated. By the Ordinary least square, (OLS) time regression analysis, the betas of the Fama French model, were estimated, using PYTHON programming language. For the Market returns, the Ghana Stock Exchange Composite Index was used. This is the major stock market index which tracks the performance of all companies traded on the Ghana Stock Exchange. For the risk-free interest rate of return, the 91-Days treasury bill backed by the Bank of Ghana (BoG), was used. To obtain and use this factor in its appropriate unit as proposed by the model, the risk-free rate was expressed on a monthly basis. (a time series data is available on the BOG, website). Then the risk-free rate is subtracted from the market return for each month. This $R_{m}-R_{f}$ factor is called the market premium. The companies in the dataset were sorted on the basis of size and Bookto- Market value (BE/ME) for every year (ending in December). The size factor is the market capitalization at each year in December, the BE/ME factor is the book value (equity) divided by market capitalization and computed at the end of each financial year. This data was obtained from financial statement of companies in GSE market reports. For companies whose book values could not be found, their unaudited account was used in place of their Annual Market Report. Sensitivity to risk factors in returns can be proxied with size and book-to-market equity, given rational pricing. The BE/ME ratio value of $0-1.99$ was considered low, $2-3.99$ as medium and greater than 4 as high. The model was applied first to assets of five companies selected from the 15 companies, then to 6 generated portfolios. The selected companies are from the Energy, Food and Beverages, Banking and Telecommunication sectors of the economy, namely; CAL Bank Ghana, Ghana Commercial Bank, Fan Milk Limited, Ghana Oil, and MTN Ghana. Risk and return for these companies have been assessed in the preliminary work done by the authors using CAPM.

The Fama French model was also applied to portfolios, for this to be done, the companies were sorted into groups. Size factor has two groups, Small and Big. BE/ME factor has three groups Low, Medium and High depending on the range of values of the ratios. These portfolios' average monthly returns are used to create the SMB and HML factors. The six portfolios are Small/Low, Small/Medium, Small/High, Big/Low, Big/Medium and Big/High. For the portfolios, OLS time regression analysis is performed using PYTHON programming language, to estimate the alpha and beta values for SMB, HML and $R_{m}-R_{f}$. The $R_{m}-R_{f}$ factor is the only factor included in the CAPM. 


\subsection{Analysis and Results}

\subsubsection{Analysis for Individual Assets}

The results for the regression analysis are displayed on the tables below. The adjusted $R^{2}$ value and the $\mathrm{P}$ value for the alpha and Betas are included on the tables.

Table 1-: Regression results for the five stocks using the Fama-French Three Factor Model, showing Intercept, Beta coefficients and adjustedR ${ }^{2}$.

\begin{tabular}{|l|l|l|l|l|l|l|l|l|l|}
\hline STOCK & $\boldsymbol{\alpha}$ & $\begin{array}{l}\mathrm{P} \text { - } \\
\text { value }\end{array}$ & $\beta$ & $\mathrm{P}$-Value $(\beta)$ & $\beta(\mathrm{SMB})$ & $\mathrm{P}$-Value & $\beta(\mathrm{HML})$ & P-value & $\begin{array}{l}\text { Adjusted } \\
R^{2}\end{array}$ \\
\hline CAL & -0.161 & 0.954 & 0.9934 & 0 & 0.0111 & 0.839 & -0.1202 & 0.382 & 0.443 \\
\hline GCB & 0.7838 & 0.761 & 1.0421 & 0 & 0.0247 & 0.621 & -0.2102 & 0.099 & 0.526 \\
\hline FML & -8.587 & 0.002 & 0.523 & 0 & 0.0345 & 0.498 & -0.2779 & 0.033 & 0.242 \\
\hline GOIL & 2.1054 & 0.41 & 1.0522 & 0 & -0.0228 & 0.645 & 0.0907 & 0.467 & 0.51 \\
\hline MTNGH & -10.55 & 0 & 0.13 & 0.62 & -0.2 & 0.19 & 0.37 & 0 & 0.62 \\
\hline & & & & & & & & & 0.47 \\
\hline
\end{tabular}

From table 1, it is shown that: FML and MTNGH were the two assets with significant alpha values. The baseline value for alpha is zero. An alpha value less than zero indicates an investment that is underperforming as compared to the market average, whereas an alpha value greater than zero indicates an investment that outperformed the market average, during a specific time period. With the exception of MTNGH all the other stocks have a significant beta coefficient. When P-values are less than significance level (i.e., 0.005) the coefficient is significant and can be used in the regression model for forecasting. Hence with $\mathrm{P}$-value $(\beta)$ being zero for all four stock prices it can be said that the Beta coefficients are significant, for those four, and can be used in the regression model for analysis.

The beta $(\beta)$ of an investment asset is a measurement of the volatility of its returns relative to the entire market. When $\beta=1$, the assetis exactly as volatile as the market, for $\beta>1$ the asset is more volatile than the market, for $\beta=0$, the asset is uncorrelated to the market, when $\beta<0$ the asset is negatively correlated to the market.

At $5 \%$ significance level, none of the five assets has a significant beta SMB coefficient. A negative coefficient for the SMB factor would indicate that the excess return is in part, due to the large size of the company or portfolio consists mainly of large cap companies. A positive SMB implies the excess return of stocks is due to the small size of the company or for portfolio, it comprises of small cap companies.

FML and MTNGH have a significant beta HML coefficient. A positive coefficient for the HML factor indicates that, the excess return is due to the company's high book-to-market ratio while a negative coefficient for the HML factor would indicate that the excess return is due to the company's low book-to-market ratio.

Basically, when $\beta(\mathrm{SMB})>0$, then the portfolio has higher expected returns if small-cap stocks outperform large-cap stocks, suggesting that the portfolio is predominantly small-cap stocks. For $\beta(\mathrm{SMB})<0$, the portfolio has higher expected returns if large-cap stocks outperform small-cap stocks, suggesting that the portfolio is predominantly largecap stocks. If $\beta(\mathrm{HML})>0$, then the portfolio has higher expected returns if high book-to-market (i.e., Value) stocks outperform low book-to-market (i.e., growth) stocks, suggesting that the portfolio is predominantly value stocks. When $\beta(\mathrm{HML})<0$, it implies that the portfolio has higher expected returns if low book-to-market (i.e., growth) stocks outperform high book-to-market (i.e., value) stocks, suggesting that the portfolio is predominantly growth stocks Moreover, the $R^{2}$ adjusted values were higher for the work on Fama French compared to values obtained for CAPM by the preliminary work done by the authors. This indicates that the extra 2 factors of the Fama French model improve the model. The average adjusted $R^{2}$ is 0.47 for the 3 - factor model, while the average $R^{2}$ value of 0.277 was obtained for CAPM in that preliminary work.

\subsubsection{Analysis for Portfolios}

Table 2-: Regression results for the Fama-French Three Factor Model. The table includes Portfolios, Intercept, Beta coefficients and adjusted.

\begin{tabular}{|c|c|c|c|c|c|c|c|c|c|}
\hline Portfolio & $\alpha$ & P-Value & $\beta(R m-R f)$ & P-Value & $\beta$ (SMB) & P-value & $\beta(H M L)$ & P-Value & Adj $R^{2}$ \\
\hline$S \mid L$ & -1.6582 & 0.339 & 0.8847 & 0.000 & 0.0288 & 0.391 & 0.0219 & 0.795 & 0.631 \\
\hline$S \mid M$ & -19.1027 & 0.000 & -0.0714 & 0.725 & 3.0325 & 0.000 & -2.036 & 0.000 & 0.965 \\
\hline$S \mid H$ & 7.296 & 0.000 & 1.3712 & 0.000 & 0.024 & 0.511 & 1.8977 & 0.000 & 0.917 \\
\hline$B \mid L$ & 0.2874 & 0.728 & 0.9993 & 0.000 & 0.0257 & 0.112 & -0.1367 & 0.001 & 0.91 \\
\hline$B \mid M$ & -5.0863 & 0.015 & 0.6727 & 0.000 & 0.0291 & 0.459 & 0.0324 & 0.743 & 0.411 \\
\hline$B \mid H$ & -8.6691 & 0.000 & 0.5126 & 0.000 & 0.0304 & 0.113 & -0.0124 & 0.796 & 0.6501 \\
\hline
\end{tabular}


From the results displayed in table 2 above, the model gives a range of adjusted $R^{2}$ values between 0.411 and 0.965 , thus the average adjusted $R^{2}$ value is 0.7668 . Two portfolios have $\alpha$ values greater than zero. This means those two portfolios performed better than the benchmark index. At $5 \%$ significance level, five (5) portfolios have significant $\beta$ values. The SMB factor is significant for only one portfolio. If the $\beta_{\text {size }}(\mathrm{SMB})$ coefficient is greater than 0.5 , it means the portfolio comprises mainly of small cap companies. Only one portfolio had a significant SMB coefficient greater than 0.5 . The $(H M L)$ coefficient, is significant for three portfolios at $5 \%$ significance level. $A(H M L)$ value greater than zero, implies that the portfolio consists of value stocks. If (HML) value is less than zero, then portfolio consists of growth stocks.

The average yearly returns for all exogenous variables are shown on the table 3 below.

Table 3: Average return,(\%) of the exogenous variables.

\begin{tabular}{|l|l|l|l|}
\hline Variables & $\boldsymbol{R m}-\boldsymbol{R f}$ & $\mathbf{S M B}$ & $\boldsymbol{H M L}$ \\
\hline Average & $-17.87 \%$ & $-3.13 \%$ & $-0.69 \%$ \\
\hline Observation & 60 & 60 & 60 \\
\hline
\end{tabular}

From the average yearly returns for the exogenous variables given on table 3 ,it can be seen that $H M L$ and SMB have negatives values. This does not support the fundamentals of the Fama French model. The basic theory of Fama et al. 1992, states that small companies outperform big companies, and that value stocks outperform growth stocks. Obtaining a negative average SMB value, means that companies with a small market capitalization value are outperformed by companies with large market capitalization value, during the period 2014-2019. A negative average value of the HML factor implies that companies with a high BE/ME-ratio (value stocks) could not outperform companies with low BE/ME-ratio (growth stocks), within the period under review. In other words, for the study period, we found out that growth stocks outperformed value stocks, and big companies outperformed small (market capitalization) companies, since we had negative HML and SMB values.

\subsection{Conclusion}

In this study, we have used the Fama French model to assess portfolio and asset returns of some companies listed on the Ghana stock exchange. Six portfolios were constructed from 15 selected companies. SMB was calculated. Risk free rates and market returns were used to obtain market premium. Size and Book to market ratios were obtained for the groups. Fama French model was applied to the portfolios. The portfolios' average monthly returns were used to obtain the SMB and HML factors. The alpha and beta values for the market premim, HML and SMB were estimated using the OLS time regression analysis.

It was found that HML and SMB yielded negatives values. This implies that value stocks could not outperform growth stocks, within the period under study. Hence the fundamentals of the Fama French model are not supported.

The small size of the Economy, and very low volume of trade, may be responsible for this result. (The Ghana Stock Exchange traded $\$ 117.28$ million in value of stocks for the financial year 2017 as compared to the New York Stock Exchange which traded \$39.786 trillion in total value of stocks). Thus, The Fama-French model seems more effective for assessment in large Exchanges.

\section{REFERENCES}

Acheampong P. and Swanzy S. K., 2015. An Empirical Investigation into the Applicability of FamaFrench Three Factor Model in Explaining Portfolio Returns: Evidence from Non-Financial Firms on the Ghana Stock Exchange. http://dx.doi.org/10.5430/ijfr.v7n1p75

Bartholdy, Jan and Peare, Paula. 2005. Estimation of Expected Return: CAPM vs. Fama and French. International Review of Financial Analysis. 14. 407-427. 10.1016/j.irfa.2004.10.009.

Fahid Ali, RongRong He, YueXiang Jiang 2018. Size, Value and Business cycle Variables. The three - Factor Model and Future Economic Growth: Evidence from an Emerging Market. Economies 6(1): 14. DOI:10.3390/economies6010014.

Fama and French Three Factor Model Definition. 2020. Retrieved 8 July 2020, https://www.investopedia.com/terms/f/famaandfr enchthreefactormodel.asp

Fama, E. F., and French, K. R., 2004. The Capital Asset Pricing Model: Theory and evidence. Journal of Economic Perspectives, 18(3), 25-46. https://doi.org/10.1257/0895330042162430

Fama, Eugene F., and French, Kenneth R., 1995. Size and Book - to- Market Factors in Earnings and Returns. The journal of Finance. Vol 1 No.1

Fama, Eugene F., and French, Kenneth R., 1992. The cross section of expected stock returns. Journal of Finance 47, $427-465$

Griffin, J. M., 2002. Are the Fama and French factors global or country specific? The Review of Financial Studies, 15(3), 783-803.

Rehnby, N., 2016. Does the Fama-French three-factor model and Carhart four-factor model explain portfolio returns better than CAPM?:-A study performed on the Swedish stock market. Thesis in the Karlstad Business School, Karlstad University. 
http://urn.kb.se/resolve?urn=urn:nbn:se:kau:diva -43784

Robert Faff, 2004. A simple test of the Fama and French model using daily data: Australian evidence. Applied Financial Economics Volume 14, 2004 Issue 2. pp83 - 92.
Sreenu, N., 2018. An Empirical Test of Capital Assetpricing Model and Three-factor Model of Fama in Indian

Stock

Exchange.https://doi.org/10.1177/0258042X187 97770

https://gse.com.gh/

https://www.annualreportsghana.com/ https://www.bog.gov.gh/

Annual Equity Traded on GSE

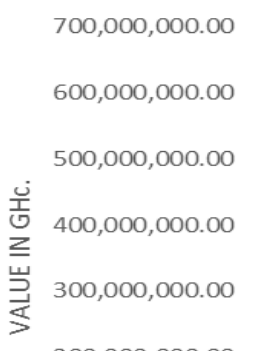

$200,000,000.00$

$100,000,000.00$

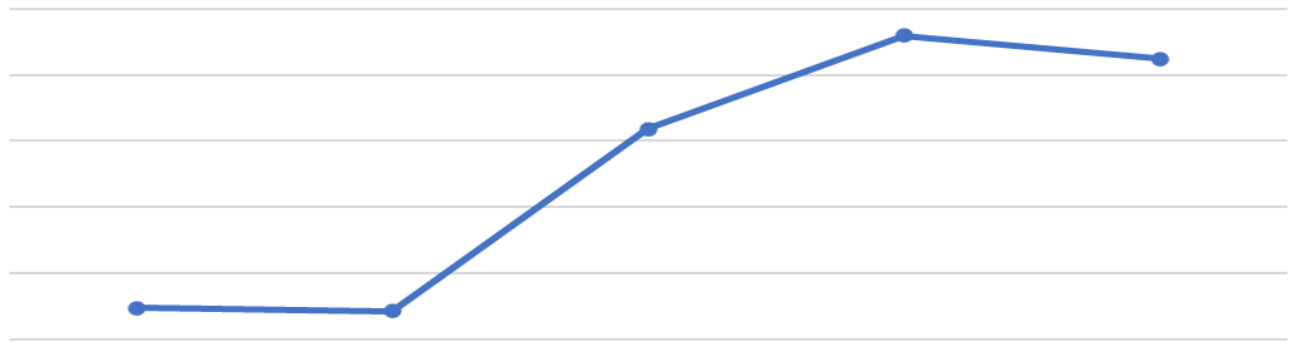

\begin{tabular}{|c|c|c|c|c|c|}
\cline { 2 - 6 } & 2015 & 2016 & 2017 & 2018 & 2019 \\
\hline$\longrightarrow$ Value Traded & $247,636,622.55$ & $242,114,791.53$ & $518,381,473.32$ & $659,359,098.77$ & $624,202,387.42$ \\
\hline
\end{tabular}

